\title{
Una poética de las ruinas: el viaje en busca de la España medieval de Frédéric Oza- nam
}

\author{
María Belén NAVARRo \\ Pontificia Universidad Católica Argentina - CONICET \\ mbnavarro@uca.edu.ar \\ ORCID: 0000-0001-8783-3555
}

\section{Resumen}

En Un pèlerinage au pays du Cid Fréderic Ozanam retrata su viaje de 1852 por tierras españolas. En esta textualización no solo se registra la experiencia personal, sino también la reconstrucción de diversos discursos que la mediatizan: referencias históricas, literarias y legendarias, especialmente vinculadas con la Edad Media y concebidas según el imaginario romántico de la época. El objetivo del presente trabajo es no solo determinar su clasificación dentro de los discursos de viajes mediante un estudio de la configuración textual, sino también analizar sus aspectos más llamativos: las isotopías y los intertextos. Este abordaje nos permitirá reconstruir el imaginario cultural del autor, su horizonte de expectativas, la funcionalidad de las isotopías e intertextos en el entramado discursivo como así también la finalidad global del libro.

Palabras clave: Ozanam, Relato de viaje, Imaginario cultural, Edad Media, Intertextualidad.

\section{Résumé}

Dans Un pèlerinage au pays du Cid, Fréderic Ozanam décrit son voyage de 1852 en terres espagnoles. Dans ce texte, il y dépeint non seulement son expérience personnelle, mais aussi la reconstruction de divers discours qui la médiatisent tels que des références historiques, littéraires et légendaires liées plus particulièrement au Moyen Âge et conçues selon l'imaginaire romantique de l'époque. L'objectif de cet article est double. Il s'agira tout d'abord de définir la classification de l'auteur dans les écritures du voyage en analysant notamment la configuration textuelle et ensuite d'examiner ses aspects les plus frappants, à savoir les isotopies et les intertextes. Cette étude permettra de reconstruire l'imagerie culturelle de l'auteur, son horizon d'attentes, la fonctionnalité des isotopies et des intertextes dans la trame discursive ainsi que la finalité globale du livre.

Mots-clés: Ozanam, récit de voyage, Imagerie culturelle, Moyen Âge, Intertextualité.

\section{Abstract}

In Un pèlerinage au pays du Cid, Fréderic Ozanam depicts his journey of 1852 through Spanish lands. It records both his personal experience and the reconstruction of

\footnotetext{
*Artículo recibido el 13/07/2020, aceptado el 25/10/2020.
} 
different discourses which intervened as well, such as historical, literary and legendary references, especially those linked to the Middle Age and perceived according to the romantic conception of the time. The aim of this paper is not only to establish its categorisation within the travel speeches by analyzing its textual configuration, but also to study its most striking aspects: the isotopies and intertexts. This approach will enable the reconstruction of the author's cultural imaginary, his horizon of expectations, the function of the isotopies and intertexts in the discursive framework as well as the overall purpose of the book.

Keywords: Ozanam, Travel narrative, Cultural imaginary, Middle Age, Intertextuality.

\section{Introducción}

Frédéric Ozanam (1813-1853) fue un abogado, académico y escritor francés, principal fundador de la Sociedad de San Vicente de Paúl y precursor de la Doctrina Social de la Iglesia, razones por las cuales fue beatificado en 1997. Efectuó en 1852 un viaje por España, sobre el cual escribe en Un pèlerinage au pays $d u$ Cid, publicado póstumamente (1869). Es un discurso con una gran riqueza en cuanto retrata un itinerario no solo espacial por lugares emblemáticos, sino también temporal, dado que se propone «recuperar» la España católica medieval, mediante las referencias a sus personajes y sucesos históricos, literarios y legendarios.

La obra de Fréderic Ozanam es abundante y variada: son muy conocidos sus trabajos teóricos sobre la literatura italiana, en particular sobre Dante y el siglo XIII -por ejemplo, Les Poètes franciscains en Italie au treizième siècle, Les sources poétiques de la Divine Comédie, Dante et la philosophie catholique au treizième siècle-, como así también sus lecciones publicadas sobre la literatura alemana, especialmente medieval -por ejemplo, Les Germains avant le Christianisme, La littérature allemande au Moyen Age-. Recientemente, en 2013, gracias al trabajo de un grupo de investigadores bajo la dirección de Didier Ozanam, ha sido editada la totalidad de sus cartas y se ha revitalizado la indagación sobre su biografía (Cholvy, 2003) y la valoración de sus estudios históricos, además de su rol social y caritativo.

No obstante, Un pèlerinage au pays $d u$ Cid ha recibido en general poca atención por la crítica literaria, más allá de comentarios vinculados con su biografía. El abordaje más próximo a nuestro objeto lo realizó recientemente Iñarrea Las Heras (2015), al incluirlo en su artículo sobre viajeros franceses a Santiago de Compostela en el siglo XIX. Mas su discursividad no ha sido sistemáticamente abordada, a pesar de ser un texto que despliega procedimientos discursivos notables y una documentación admirable, que demuestra un conocimiento profundo del autor sobre la literatura española medieval cuando recién en España se comenzaba a investigar con criterios filológicos rigurosos. De este fecundo diálogo entre el itinerario, la historia y la literatura, surge este texto con una mirada muy marcada sobre España y el cristianismo. 
Con el objetivo de valorar adecuadamente la obra y ubicarla en su contexto, consideramos primordial estudiar sus elementos formales constitutivos y así determinar su clasificación genérica dentro de las categorías de los libros o escrituras de viaje. No es un problema con repercusiones meramente inmanentes, dado que el género discursivo funciona como condicionante de un horizonte de expectativas para los lectores y brinda un marco para la interpretación y valoración de la obra, en tanto paradigma, en continuidad con ciertos textos y en contraste con otros.

Las escrituras de viaje son textos cuya tipología genérica presenta cierta complejidad, dada su hibridez y el carácter fronterizo de su grado de factualidad y ficcionalidad. Por su perspectiva formal centrada en el texto, aplicaremos como marco teórico el método y las categorías teóricas propuestas por Sofía Carrizo Rueda (1997, 2008 $)$, quien distingue entre la literatura, las crónicas, las guías y los relatos de viajes, a partir de sus componentes formales, especialmente las secuencias dominantes, la construcción del rol del narrador y la finalidad del texto. Esto permite diferenciar con claridad, por un lado, las autobiografías, las crónicas y las guías de viaje por su materia y objeto; por otro, la literatura de viajes y el relato de viajes, que de manera preliminar definiremos respectivamente como un discurso ficcional predominantemente narrativo y un discurso no ficcional predominantemente descriptivo, aunque presentan otros rasgos axiales, como profundizaremos en el apartado 2.5.

A modo de hipótesis basal, proponemos que Un pèlerinage au pays du Cid pertenece al género denominado relato de viajes. Para demostrarlo, es preciso en la primera parte analizar desde una perspectiva formal sus componentes constitutivos en lo que respecta a la construcción del discurso: el objeto del viaje, el viajero enunciador, el enunciatario y la estructura textual. A partir del resultado de este examen, podremos justificar su encuadre genérico y, en consecuencia, proponer un marco de interpretación según el horizonte de expectativas correspondiente.

Una vez fundamentada su categorización como un relato de viajes, en la segunda parte se reflexionará sobre la representación de España efectuada en $U n$ pèlerinage au pays du Cid mediante un abordaje de las redes isotópicas y de ciertos intertextos presentes, con el objeto de delimitar su funcionalidad en relación con la finalidad global de la obra y sus efectos, enmarcada dentro del imaginario cultural francés de mediados del siglo XIX, con el cual dialoga.

\section{La configuración del discurso del viaje: análisis de elementos constitutivos}

\subsection{El viaje: fechas y lugares}

En primer lugar, es preciso delimitar el objeto del texto Un pèlerinage au pays $d u$ Cid. El paratexto principal, el título, establece un tipo de viaje muy particular: el religioso, en específico, la peregrinación. Se podría entonces anticipar un

\footnotetext{
${ }^{1}$ La teoría de Carrizo Rueda es retomada por otros críticos literarios, en el ámbito español especialmente por Luis Alburquerque-García (2006, 2011), quien amplía el aspecto de la intertextualidad propia del género, que abordaremos en el apartado 3.2.
} 
destino devocional, pero también un posible sentido metafórico, la romería de la vida, inspirado en el tópico literario del Peregrinatio vitae. Además, se propone el destino de la travesía: «al país del Cid». Por un lado, es llamativo el procedimiento metonímico operado al referir a España mediante uno de sus héroes medievales; por otro, el aparente contraste entre el objetivo religioso del viaje y la referencia épica.

En segundo lugar, se pueden reconstruir intratextualmente algunos datos precisos del viaje fáctico efectuado por Frédéric Ozanam mediante los paratextos que encabezan cada apartado, donde se indican las fechas y los lugares. Cabe señalar que este es un rasgo que Alburquerque-García (2011: 18) considera axial para los libros de viaje: los paratextos funcionan como recursos para la construcción de la verosimilitud y la autenticidad del itinerario. En el caso de Ozanam, dichos paratextos organizan el relato: «Gavarnie, 21 août; Biarritz, $1{ }^{\text {er }}$ septembre 1852» respecto a «I. Avant-scène, les Pyrénées et la mer», «Fontarabie, le 16 novembre. - Miranda de Ebro, le 17» para «II. Le chemin de Saint-Jacques», «Burgos, le 18 novembre 1852» para «III. La ville des héros», «Burgos, le 19 novembre 1852» para «IV. La ville des rois», «Burgos, le 20 novembre 1852» para «V. La ville de la Vierge» y «Pont de Béhobie, le 21 novembre» para «VI». Tales fechas ya informan un dato peculiar: se evidencia un tiempo transcurrido sin texto entre las visitas efectuadas a la frontera francesa y el ingreso a España -de septiembre a noviembre- sin ningún tipo de justificación explícita a nivel textual. Asimismo, el prólogo, denominado «Burgos», carece de este tipo de paratexto de anclaje espaciotemporal y la voz enunciadora se construye retrospectivamente desde el punto de vista de la posición temporal, en términos de Genette (1989: 274), como «narración ulterior», en otras palabras, con el itinerario concluido.

Estos encabezados sintetizan los hitos del camino, pero dentro del relato se registran otras ciudades y pueblos, generalmente junto a sus respectivas descripciones, cuya extensión varía según su importancia histórica o literaria, dado que no solo se detiene en los aspectos arquitectónicos o culturales, sino que además sintetiza los eventos acaecidos -o imaginados- en esos enclaves, muchas veces citando fragmentos textuales e incluso expresando su opinión sobre ellos.

\subsection{Prólogo «Burgos»: el viajero peregrino, el objetivo y el obstáculo}

Un pèlerinage au pays $d u$ Cid comienza con un prólogo que evoca la tradición de origen medieval del peregrinaje a Santiago de Compostela, pero de una manera inusual; se detiene en un detalle cotidiano y hasta legendario: la costumbre de la recolección de conchas en la playa como una especie de souvenir que luego los peregrinos mostraban a su familia y vecinos (Ozanam, 1869: 2). El enunciador declara entonces la intención que parece haber tenido al planificar este viaje: «Moi aussi j'ai rêvé le pèlerinage de Saint-Jacques. Je me réjouissais de voir la vieille Espagne chrétienne, cette Espagne libre, pauvre, délaissée, qui subit moins profondément l'empreinte de l'étranger»(Ozanam, 1869: 2). Describe a grandes rasgos los hitos que tendría tal camino: Burgos, Oviedo, Santiago, pero confiesa el obstáculo: «Mais une volonté qui dispose de nous sans nous devait 
m'arrêter à la première station, et mon pèlerinage finir, non plus au tombeau de saint Jacques, mais au pays du Cid» (Ozanam, 1869: 2-3). Es la única afirmación textual acerca de un impedimento mayor que le imposibilitó efectuar el viaje pensado y que además explicaría el lapso transcurrido entre la llegada a la zona de los Pirineos y el cruce a España. La razón efectiva debe ser reconstruida extratextualmente, en sus cartas: el mal clima y su débil estado de salud lo obligó a guardar reposo, durante el cual aprovechó para instruirse en la historia y la literatura española; conocimiento que lo ayudó a inclinarse por Burgos como destino, por presentar todas las variables de su interés: la reconstrucción de la «vieja» y «cristiana» España (Ozanam, 1865: 404, 410, 422).

Para finalizar este prólogo, Ozanam (1869: 3) indica que ha vuelto de esta peregrinación por Burgos sin conchas, pero:

pleines de ces feuilles légères où le voyageur a crayonné ses premiers souvenirs, se promettant vainement de les retoucher plus tard. Je ne puis rien offrir de plus à mes amis, à ceux de mon voisinage : j'entends ce voisinage de l'esprit et du cœur qui unit aujourd'hui beaucoup de chrétiens, et qui leur fait prolonger ensemble la veillée avec confiance, malgré de bien mauvaises nuits.

Tales hojas son, en efecto, sus notas de viaje, que según las biografías consultadas retomó en Italia, en 1853 mientras convalecía, para componer Un pèlerinage au pays du Cid, publicado póstumamente por su esposa (Cojazzi, 1933: 193; Romero Carranza, 1976: 444). Más allá de la presentación poética de su intención y viaje, es cierto que escribió durante el itinerario: a pesar de que no se conserven ninguna de tales notas -a diferencia de otros viajes previos-, algunos pasajes de las cartas enviadas en ese período contienen fragmentos literales o muy semejantes a las descripciones o impresiones incluidas en la versión final de Un pèlerinage au pays du Cid, tales como la descripción del circo de Gavernie en la carta a A. M. L'Abbé Maret de Biarritz, 14 septiembre 1852 (Ozanam, 1865: 395), la catedral de Burgos en la carta a su hermano Charles desde Burgos, 18 de noviembre de 1852 (Ozanam, 1865: 417-419), o el monasterio de Las Huelgas en la carta a Ampere desde Bayonne, 25 de noviembre de 1852 (Ozanam, 1865: 424-425).

Si bien se podría simplemente aceptar sus declaraciones de manera literal, es llamativo el hincapié realizado en el prólogo respecto al sema 'noche' caracterizada negativamente- como momento para compartir souvenirs: «des longues veillées d'hiver» en el caso de los peregrinos de antaño y «mauvaises nuits» de los cristianos que lo acompañan en la vigilia actualmente. Evidentemente se trata de una asociación del peregrino medieval con el peregrino de 1852 en un plano metafórico: es un autor apologético católico y su intención es recuperar los valores de la Europa cristiana en un contexto poco propicio: Francia en la primera mitad del siglo XIX. El país vivía una profunda crisis religiosa a partir de las primeras reformas laicas seculares, iniciadas violentamente por la Revolución francesa mediante la descristianización y el anticlericalismo promovidos con su Culto de la Razón y del Ser Supremo, la constitución civil del clero y la divulgación de 
posturas religiosas no cristianas, tales como el agnosticismo, el ateísmo y el deísmo. Si bien en 1852 la situación de los católicos no era tan grave como en el «Reinado del Terror», sí había una notable disminución del fervor religioso, sumada a la desilusión que sentía Ozanam por el fracaso de la Segunda República Francesa -por la crisis económica, la difusión de las ideas socialistas y la discordia cívica-, que culminaría en diciembre de ese año con el golpe de Estado de Luis Napoléon Bonaparte y la instauración del Segundo Imperio, además de la división política interna de los católicos (Cholvy, 2003; Romero Carranza, 1976: 30-82, 307-414). Frente a este panorama poco esperanzador, tanto política, religiosa como vitalmente -en lo que concierne a su enfermedad-, en esta «noche» de su vida y del siglo, desea conocer - ¿recuperar?- la España medieval, «cristiana vieja». Por lo tanto, la vigilia retratada en el prólogo podría leerse más allá de lo literal como una vigilia por la cristiandad y las tradiciones ${ }^{2}$.

Otro aspecto sobre el cual decide callar tanto en el prólogo como en el resto del libro, aparte de su enfermedad, es su compañía durante el viaje. Varía la persona gramatical que relata: utiliza la primera persona singular como así también la tercera impersonal del francés «on», pero también hay algunas marcas de una primera persona plural que no son recursos para involucrar el lector sino indicios concretos de otras personas en la experiencia, por ejemplo: «L'hiver venu sur l'aile des vents nous ferme décidément la route de Compostelle. Les conseils de nos amis ne nous permettent pas de pousser jusqu'à Madrid» (Ozanam, 1869: 145). Sin embargo, es imposible a nivel textual inferir quiénes eran; al recurrir a las cartas y biografías, se descubre que se trataba de su esposa Amélie y su hija Marie, quien tenía siete años por aquella época (Ozanam, 1865: 397, 428, 429; Cojazzi, 1933: 193; Romero Carranza, 1976: 444; Cholvy, 2003).

\subsection{La estructura del relato}

Externamente el relato se divide en siete apartados, aunque solamente seis tratan estrictamente el itinerario y son aquellos que están secuenciados con números romanos. El prólogo simplemente se titula «Burgos», sin mayor indicación paratextual temporal, a diferencia de los otros, mientras que el epílogo lleva número, pero no un título. La estructura del planteo es circular, tal como lo fue su travesía de esos seis días entre el 16 y el 21 de noviembre: de Francia a Burgos y nuevamente de regreso a la frontera pirenaica, es decir, que el relato propiamente dicho abre -en el apartado «I. Avant-scène, les Pyrénées et la mer»- y culmina en Francia - en $\ll \mathrm{VI} »-$.

\footnotetext{
${ }^{2}$ En su artículo, Iñarrea Las Heras comenta acerca de viajeros franceses del siglo XIX que emprendieron un viaje a Santiago de Compostela, en general posteriores a Ozanam, aunque también lo incluye como viajero frustrado, para analizar la mengua de peregrinos en aquella época y la motivación de estos pocos viajes. En varios casos encuentra que demuestran una visión profundamente católica que determina su cosmovisión: «Les parcours qu'ils ont réalisés dans ce territoire leur ont fourni aussi l'occasion de réaliser des réflexions qui manifestent une prise de position nettement conservatrice sur tous les aspects qu'on vient de nommer» (Iñarrea Las Heras, 2015: 319). Considera que se trata una reacción contra el contexto anticlerical (2015: 319-321).
} 
Esta misma circularidad se observará a nivel intertextual, dado que el apartado I concluye con la evocación del salmo 92, mientras que en el apartado VI culmina con un poema a la Virgen: «Muy graciosa es la Doncella» de Gil Vicente. Además, el autor se declara consciente del procedimiento: «Tout ceci est peut-être bien solennel pour un début de voyage; mais on sait que les pèlerinages s'ouvrent par des psaumes» (Ozanam, 1869: 14), «Nous avions commencé notre pèlerinage par un psaume. Il convenait de le finir par un cantique» (Ozanam, 1869: 151). También recurre a la circularidad en lo temático: en el primer apartado refiere a la naturaleza como obra de un Dios artista, mientras que en el quinto apartado presenta a una mujer en la catedral, sentada a su lado mientras reza, que le pregunta acerca del destino de las obras arquitectónicas piadosas en el Fin de los Tiempos y la posibilidad de que perduren en la Jerusalén celestial, reflexión -con mucha probabilidad ficcionalmente delegada - con la que concluye el apartado y su recorrido por Burgos:

Une femme chrétienne qui visitait aussi la cathédrale de Burgos, et qui avait aussi prié de même à beaucoup de sanctuaires, demandait ce que Dieu ferait, au dernier jour, de ces admirables ouvrages élevés à sa louange par la tendre piété de tant de générations. Le feu qui doit purifier la terre foudroiera-t-il ces tours qui montaient pour le conjurer; ces chevets d'église gardés par les anges, ces madones si pures et ces saints si humblement prosternés devant elles? Et d'ailleurs, celui qui fait gloire de s'appeler le souverain artiste aura-t-il le courage de détruire tant de mosaïques et de fresques où rayonne l'éternelle beauté? Pourquoi ces monuments n'auraient-ils pas aussi leur immortalité ou leur résurrection? Et qui sait si, miraculeusement sauvés, ils ne devraient pas faire l'ornement de la Jérusalem nouvelle que saint Jean nous représente toute resplendissante de jaspe et de cristal? (Ozanam, 1869: 142-143).

A nivel del itinerario, opta por no centrarse únicamente en el territorio español sino también retratar el origen, a pesar de que el objeto descrito en el primer apartado - la naturaleza de los Pirineos- no condiga con lo predominante en el resto de la obra, tanto en materia como en estilo -aunque se estudiará su vinculación a nivel isotópico en el apartado 3.1.1.-.

No existe una correspondencia entre la cantidad de días y la división de los capítulos, ni siquiera una proporción en cuanto a su extensión. La división es claramente temática según los rasgos de los lugares visitados que desea destacar y el grado de detalle que brindará de ellos. De esta manera, cada día en Burgos se distribuye en un apartado diferente según la índole de su materia: heroica, real o mariana. Pero se sabe por sus cartas que esa organización de la visita es un artificio discursivo y que no fue realmente el orden en el cual visitó la ciudad (Ozanam, 1865: 417-420).

Asimismo, si bien el último apartado se plantea como el relato del regreso a la frontera francesa, las descripciones son breves, dado que los pueblos ya ha- 
bían sido retratados previamente en la primera visita, en el segundo apartado. La función de la inclusión de esta parte del itinerario no responde a una necesidad del trayecto, cuya narración podría haber concluido en Burgos; más bien actúa como epílogo y tiene una función ideológica explícita, que abordaremos en 2.5.

\subsection{Construcción del enunciador y del enunciatario del relato}

Como voz a cargo de la organización y construcción del relato, en el resto de los apartados que narran propiamente la travesía, Ozanam se construye, en relación con la historia ${ }^{3}$, como un narrador homodiegético en lo que concierne a su propia experiencia de viaje, que es el marco envolvente, pero heterodiegético cuando relata las anécdotas históricas y literarias que cumplen una función descriptiva subordinada al itinerario, como secuencias incrustadas.

Si se analizan aisladamente los núcleos narrativos de su itinerario, el relato contiene escasas anécdotas personales y todas ellas se encuentran supeditadas a representar alguna característica llamativa de España, como sucede cuando comenta acerca del medio de transporte de las mulas y sus nombres literarios:

Qui n'a entendu parler des attelages espagnols, de cette longue file de mules attachées deux à deux, que le mayoral gouverne du haut de son siège avec autant de dextérité que de hardiesse, mais non sans les animer par une conversation soutenue, par des noms flatteurs, des cris pathétiques: «Brava, Capitana! Adelante, Catalana! Ánimo, Pastoral». Tant fut procédé du geste et de la voix, que Pastora tomba sur le flanc et ne se releva que sous les sifflements du fouet. Ô pays de Garcilaso et de Montemayor ! terre classique de l'églogue, pouvez-vous supporter cette profanation du nom de vos bergères ! (Ozanam, 1969: 19-20).

Para representar el peligro del camino entre San Sebastián y Burgos, primero resume la leyenda de Bona de Pisa y el auxilio divino que precisó para concretar su peregrinaje a Santiago (Ozanam, 1869: 24-25), luego traza el paralelo con su propia circunstancia de viaje de 1852 , pero considera a esta última aún más apremiante y en necesidad de la misma ayuda:

Il ne fallait pas moins qu'une garde céleste pour rassurer les pèlerins du douzième siècle. Les carabiniers de la reine d'Espagne, qui nous escortent depuis hier, nous tranquillisent moins qu'ils ne nous alarment, en nous rappelant que nous voyageons en compagnie de dix-sept millions de réaux, par des chemins où l'on n'est pas sans rencontrer quelque soir six escopettes derrière un buisson (Ozanam, 1869: 2526).

\footnotetext{
${ }^{3}$ El narratólogo Gérard Genette (1989) clasifica al narrador según su relación con la historia, en otras palabras, su presencia o ausencia en la historia que cuenta (homodiegético y heterodiegético respectivamente).
} 
Salvo en estas contadas ocasiones, el enunciador más bien se presenta como espectador de las ciudades, a las cuales describe primero de manera general, centrándose en su actividad comercial y religiosa, para luego focalizarse en lugares o monumentos de hitos históricos o legendarios, explicar sus características arquitectónicas significativas, pero sobre todo se detiene en sintetizar la anécdota histórica, legendaria o literaria, apelando incluso a la cita directa de diálogos de las obras para vivificar las escenas. Véase, por ejemplo, el tratamiento que reciben las cabezas sin cuerpo en Burgos, asociadas a la historia de los siete Infantes de Lara (Ozanam, 1869: 35-37): allí explícitamente indica la importancia de la literatura legendaria como criterio de selección para el itinerario:

Si maintenant votre guide, plus jaloux de suivre l'ordre de la légende que de ménager vos pas, vous fait descendre de la hauteur solitaire où s'élève l'arc de Fernan sur la place de la cathédrale, il vous montrera au portail du noble édifice une file de têtes sans corps (Ozanam, 1869: 35).

Luego de indicar la fuente -Histoire véritable des sept infants de Lara-, sintetiza la historia y cita en notas ocho versos del romance «Yantando con Almanzor» en español (Ozanam, 1869: 37).

Nos encontramos ante un narrador que no esconde su cultura; por el contrario, suele indicar las fuentes bibliográficas de los datos incorporados, tanto noliterarias ${ }^{4}$ como literarias -de estas nos ocuparemos específicamente en el apartado sobre los intertextos en 3.2.-, lo cual lo caracteriza inequívocamente como profesor e investigador al fundamentar su testimonio, a la manera de las exigencias y de los métodos históricos vigentes:

Il va directement aux sources. Il fouille, comme il nous le dit, dans les histoires particulières, dans les vies des saints, dans les chroniques des villes. Il a laissé, de sa fine écriture, des notes presque innombrables. Il possède une connaissance étendue des auteurs classiques, des écrivains de la décadence romane, des Pères de l'Eglise. [....] Veut-il parler de la littérature d'un pays, il a le scrupule de visiter ce pays même. (Baudrillart, 1912: 45)

Incluso se permite realizar recomendaciones en el caso de la reconstrucción de la historia del Cid: «Il la faut lire dans le Poëme du Cid, plus ancien que les Romances, plus ancien que la Chronique, et dont le texte mutilé débute par la disgrâce du héros »(Ozanam, 1869: 42), o los matices que establece respecto a la

\footnotetext{
${ }^{4}$ Como fuentes no-literarias, principalmente alude a Apuntes sobre Burgos, Apuntes históricos sobre la Cartuja de Miraflores de Arias, History of Spanish littérature, tomo I de Ticknor (respecto a Juan II y su influencia en la poesía), la introducción de M. Pidal al Cancionero de Baena, un artículo de M. Leopoldo de Gueto, Revue des Deux Mondes, del 15 mayo de 1853 (Ozanam, 1869: 31, 83, 90, 96). Aunque en su carta a Eugène Rendu (Biarritz, 28 octobre 1832), declara otras lecturas adicionales: «Je viens de lire deux Itinéraires, l'un de M. de Laborde, l'autre de M. de Custine, le livre de M. Weiss sur la décadence de l'Espagne, un volume de Ticknor sur la littérature de ce pays» (Ozanam, 1865: 404).
} 
veracidad del material legendario o tradicional, como en el caso de Alfonso VIII y la fundación de Santa María la Real de las Huelgas: «Le vrai et le faux se mêlent dans ces récits. L'épisode de la belle juive n'a rien d'historique, et le monastère ne s'éleva point pour apaiser le courroux du ciel, déclaré par la défaite d'Alarcos; car il la précéda de plusieurs années» (Ozanam, 1869: 71).

Emite varios comentarios metadiegéticos. Principalmente los emplea retóricamente como captatio benevolentiae contra el tedio que sus informaciones históricas puedan generar, por ejemplo:

Ne craignez pas que j'abuse de mes avantages, et, pour avoir acheté tout à l'heure l'Histoire, véritable des sept infants de Lara, au coin du marché aux herbes, chez une marchande de ballades qu'entourait une nombreuse clientèle de muletiers, ne pensez pas que je menace de vous répéter d'un bout à l'autre ce long récit (Ozanam, 1869: 35).

Por otra parte, el enunciatario es textualizado mediante la segunda persona gramatical «vous», a quien generalmente se le pide paciencia, se le aconseja moderación en sus prejuicios:

Vous avez ouï beaucoup médire de l'Espagne, et vous craignez qu'au retour de tant de courses je ne trouve guère meilleur gîte ni meilleure chère que les compagnons du Cid, campés sur la grève de l'Arlanzon. Mais laissez-moi venger ce beau et trop calomnié pays (Ozanam, 1869: 58).

$\mathrm{O}$ de quien supone determinada reacción: «Vous me reprochez probablement de discourir devant les grilles de l'abbaye, au lieu de vous laisser pénétrer sous ses cloîtres dont vous avez ouï décrire les merveilles. On vous a vanté surtout les claustrillas et leurs arcades romane [...]»(Ozanam, 1869: 77).

Otro procedimiento peculiar, que rompe con la posición temporal del narrador y que emplea como recurso, es hacer presente al lector en el lugar que describe, como si lo estuviera realmente acompañando o se tratara de un relato simultáneo, por ejemplo, en la siguiente cita, donde aparenta querer aprovechar la travesía previa para educar sobre la historia de la persona cuyo monumento u obra arquitectónica se va a visitar:

De Burgos à la chartreuse, la route est longue, et j'en profite pour vous entretenir du roi Juan II, non sans quelque justice, puisque nous allons visiter des lieux pleins de sa mémoire, puisque la splendeur poétique de son règne se réfléchira sur les œuvres d'art qui nous charmeront (Ozanam, 1869: 85).

El desplazamiento no solo es espacial (como en Ozanam, 1869: 39, 68, 94), también es temporal: «Nous voici donc en plein quinzième siècle» (Ozanam, 1869: 86). Evidentemente, todos estos recursos responden a una función comunicativa del narrador con el narratario (Genette, 1989: 329).

Respecto a los rasgos explícitos del enunciatario, en general Ozanam parece dirigirse a los cristianos, como ya se ha analizado en el prólogo. Cuando describe patéticamente el circo de Gavernie, expresa su incredulidad de que los ateos 
-discursivamente un referente en tercera persona y no un alocutario- puedan persistir ante la revelación de la maravilla de la Creación divina: «La voix des cascades gémissait comme une prière sans fin: s'il restait encore des athées, c'est ici que je voudrais les amener pour les voir tomber à genoux, terrassés et ravis» (Ozanam, 1869: 6). Sin embargo, luego admite la posibilidad de un lector nocatólico antes de referir en estilo directo su plegaria a la Virgen María en la catedral de Burgos: «si la prière d'un catholique vous scandalise, ne m'écoutez pas» (Ozanam, 1869: 140). De todos modos, es evidente que no contempla la posibilidad de un lector infiel, a quien presenta como enemigo de la Europa cristiana, en el plano histórico: «En 872, les infidèles la saccagèrent et massacrèrent sous ses cloîtres l'abbé Etienne avec deux cents moines» (Ozanam, 1869: 47), pero también en el plano coetáneo: «Les côtes du Maroc leur sont promises; et leur armée se retremperait dans la croisade civilisatrice qui achèverait de faire de la Méditerranée un lac chrétien» (Ozanam, 1869: 149).

También presupone en el lector cierto conocimiento literario, dado que las referencias a obras literarias suelen ser una constante en el relato, y muy variada, registrándose remisiones a la literatura clásica -griega y latina-, italiana especialmente Dante y la poesía provenzal-, española medieval y del Siglo de Oro, como se estudiará en el apartado de intertextos (3.2.). Suele explicar las alusiones, aunque no siempre, de allí que se suponga un narratario culto; por ejemplo, la referencia mítica aplicada al mercado de San Sebastián: «Les fruits du pays, les vins enfermés dans des outres, arrivent sur des chariots à bœufs, dont les roues pleines et sans rayons représentent assez bien les équipages d'Alaric et d'Attila» (Ozanam, 1969: 18).

Asimismo, suele comparar los paisajes o edificios con otros lugares de $\mathrm{Eu}$ ropa, especialmente de Francia (Ozanam, 1869: 17, 79), pero también se mencionan Italia (Ozanam, 1869: 5) ${ }^{5}$, Suiza (Ozanam, 1869: 7-8), Inglaterra (Ozanam, 1869: 64, 136); en general son lugares que el autor ha visitado previamente ${ }^{6}$, pero también funcionan como indicio del enunciatario esperado y de su respectivo marco de experiencia como parámetro de las comparaciones.

\subsection{Definición del género discursivo de Un pèlerinage au pays du Cid: el rela- to de viajes}

Habiendo ya analizado la configuración básica del texto en cuanto a sus elementos constitutivos fundamentales -estructura, objetivo, enunciador y enunciatario-, podemos delimitar el género discursivo de Un pèlerinage au pays $d u$ Cid.

\footnotetext{
${ }^{5}$ La mayor parte de las comparaciones con Italia suele ser más bien de índole cultural, en lo que concierne al arte plástico o poético, como se tendrá oportunidad de observar en el apartado 3.2.

${ }^{6} \mathrm{El}$ único caso llamativo es el de Siberia, que probablemente responda al imaginario cultural, más que a una experiencia vivencial: «La nuit nous dérobe la florissante ville de Vitoria, et le jour nous surprend à Miranda de Ebro, sur la frontière de la vieille Castille. Nous pouvons nous croire sur la frontière de Sibérie» (Ozanam, 1869: 20).
} 
Dada la hibridez y el carácter fronterizo de su grado de factualidad y ficcionalidad, las escrituras de viaje presentan una compleja tipología genérica, que se ha investigado en detalle recién en los últimos treinta años. No es nuestro propósito en este momento dirimir sobre la teoría del género escrituras de viaje, sino contextualizar la utilidad de aplicar algunas de las nociones al texto de Ozanam para poder ahondar en su interpretación. Nosotros adherimos a las definiciones propuestas por Sofía Carrizo Rueda (1997, 2008), por su perspectiva formal, que juzgamos más pertinente por atenerse a cuestiones textuales, en particular las secuencias dominantes, la construcción del rol del narrador y la finalidad.

Mientras la literatura de viajes implementa una modalidad completamente ficcional en la cual «el itinerario se subordina a las vicisitudes de la existencia de los personajes» (Carrizo Rueda, 2008: 10), en otras palabras, las descripciones están siempre subordinadas al desenvolvimiento de la trama, el relato de viajes se define específicamente como:

[...] un discurso narrativo-descriptivo en el que predomina la función descriptiva como consecuencia del objeto final, que es la presentación del relato como un espectáculo imaginario, más importante que su desarrollo y su desenlace. Este espectáculo abarca desde informaciones de diversos tipos, hasta las mismas acciones de los personajes. Debido a su inescindible estructura literario-documental, la configuración del material se organiza alrededor de núcleos de clímax que, en última instancia, responden a un principio de selección y jerarquización en el contexto histórico y que responde a expectativas y tensiones profundas de la sociedad a la que se dirigen (Carrizo Rueda, 1997: 28)

En consecuencia, el relato de viajes se configura como un texto de naturaleza dual, en el cual la descripción no se construye subordinada al desenvolvimiento de la trama, sino como verdadero centro del discurso, en tanto el objetivo es presentar «un espectáculo de un fragmento de mundo» (Carrizo Rueda, 2008: 20) ${ }^{7}$. Las historias, vividas o recogidas, funcionan también como una operación descriptiva en tanto representan conductas humanas o matices del espacio recorrido. Toda descripción implica una selección que depende de ciertas posturas e intenciones del emisor, actúa como indicio ideológico, de aquello que se calla o desdibuja, por lo tanto, es esencial aplicar la perspectiva del estudio formal de los componentes del discurso y sus funciones, tal como hemos hecho en los apartados previos, para indagar en el texto y en su contexto los posibles motivos de esta selección.

\footnotetext{
${ }^{7}$ Cabe señalar que el predominio de la descripción no quiere decir dominio absoluto, ya que esa es la especificidad de las guías de viajes, que carecen de la huella subjetiva de las peripecias del viajero. Por el contrario, en las crónicas hay un predominio del relato de los acontecimientos y a este fin queda subordinada la función descriptiva de carácter informativo. A su vez, la autobiografía se centra en el relato de una vida, durante el cual eventualmente puede haber viajes, pero las experiencias personales del viajero prevalecen sobre las circunstancias del viaje (Alburquerque-García, 2006: 79-80).
} 
A partir de los elementos constitutivos de esta definición, podemos afirmar que Un pèlerinage au pays $d u$ Cid se clasifica como un relato de viajes. En primer lugar, ya se ha podido observar el poco protagonismo que tiene el itinerario realizado por Frédéric Ozanam como experiencia vital; si bien son el marco envolvente o el eje rector del relato en términos de la lógica discursiva, las anécdotas personales son escasas y con un desenlace ya conocido, sin tensión narrativa.

En segundo lugar, dichos sucesos se subordinan siempre a una función descriptiva, a la construcción de una imagen de España, como la situación con las mulas o el peligro en el camino previamente mencionados. Junto con las descripciones del paisaje, de la arquitectura o de la organización urbana, abundan las referencias históricas, literarias y legendarias, en las cuales el autor suele demorarse, recreando poéticamente los acontecimientos para que, tal como él mismo indica, nos transporten en el tiempo y les brinden vida a las ruinas:

Vous me soupçonnerez de glisser ici, sous le couvert d'un voyage, les chapitres détachés d'une histoire de la littérature espagnole. Me garde le ciel de cet excès de perfidie ! Mais comment nierai-je que pour moi l'attrait, la magie du voyage est de me transporter non-seulement dans d'autres lieux, mais en d'autres siècles? Ces grandes contrées historiques ne seraient à mes yeux que de lamentables cimetières, si je ne faisais revivre en passant les générations qui les ont peuplées. Et je ne sais enfin ranimer ces générations qu'en leur rendant la parole, surtout la parole des poètes, qui exprime avec plus de naïveté, de verve et d'éclat, la pensée de tous (Ozanam, 1869: 85; la cursiva es nuestra).

En tercer lugar, se evidencia una intención del autor, marcada por una ideología que dispone la selección y jerarquización en función de las expectativas y tensiones de la época para presentar un espectáculo de un fragmento de mundo: a partir de estas declaraciones del narrador (explícitas o implícitas), se comprende que el primer objetivo de Ozanam es recuperar la España medieval cristiana, que se defendió de la invasión musulmana, que conserva sus tradiciones ancestrales y respeta el culto católico. Como es propio del imaginario romántico de su época, considera que el mejor medio para conocerla, valorarla y recobrarla es la literatura $\mathrm{y}$, en segundo lugar, la historia. Por eso se regocija ante las figuras del Cid y de Fernán González al mismo tiempo que apenas le dedica alguna palabra a eventos o sitios contemporáneos. Sin embargo, su finalidad ulterior es demostrar el protagonismo del cristianismo en el progreso de la humanidad y, para ello, debe defender la Edad Media como un momento decisivo en la historia. Esa es la función ideológica que organiza el relato y los contrastes de las isotopías del texto, como demostraremos en el apartado 3.1.3.

Si bien existen algunos comentarios claramente ideológicos a lo largo del relato, el más evidente se presenta en el desenlace del itinerario, en el último apartado, en el cual aprovecha la demora de la inspección de los pasaportes en la frontera de Béhobie para realizar una exhortación a España acerca de su misión: 
Oh! Que ce serait bien le lieu de disserter, pendant qu'avec une lenteur solennelle on vise nos passeports ! Et pourquoi, dans un temps où les peuples ont tant de conseillers, refuserais-je mes conseils à un peuple que je connais depuis huit jours ? Je dirais à l'Espagne qu'elle a fait avec le Saint-Siège une paix bonne et sage; qu'elle a noblement défendu son indépendance contre les intéressés qui la voulaient mettre en tutelle; qu'enfin elle a enseigné à des nations plus expérimentées qu'elle, comment on peut maintenir la tradition de l'autorité sans étouffer les libertés publiques. Il lui reste à reprendre, parmi les puissances chrétiennes, la grande fonction qui lui fut assignée. Ce n'est pas en vain qu'un de ses rivages regarde l'Italie, elle n'y doit plus rêver de conquêtes, mais elle n'y doit pas permettre les invasions du Nord. Un autre rivage se tourne vers l'Amérique, dont Christophe Colomb n'a pas trouvé les clefs pour qu'elles tombent aux mains des marchands de houille et de coton. En moins de vingt-cinq ans, la Turquie a réparé les désastres de Navarin; l'Espagne ne peut pas laisser éternellement fumer les débris de Trafalgar. Enfin, d'un troisième côté, l'Espagne découvre l'Afrique, où l'Alcoran vaincu essaye de ranimer le fanatisme de ses sectaires. Les Espagnols justifient leurs combats de taureaux comme une école de courage qui entretient les qualités militaires de la nation. Ils ont à leur portée et nous leur avons fait une meilleure école de soldats; les côtes $d u$ Maroc leur sont promises; et leur armée se retremperait dans la croisade civilisatrice qui achèverait de faire de la Méditerranée un lac chrétien (Ozanam, 1869: 148-149; la cursiva es nuestra).

Primero, Ozanam resalta tres cualidades de España: la paz con la Santa Sede, la independencia y la conservación de la tradición de la autoridad sin dañar las libertades públicas. Su apreciación es claramente subjetiva y opera con base en el contraste implícito con la situación de Francia, que en aquella época luchaba por conseguir un equilibrio en esas tres características, especialmente en lo que concernía al Vaticano, las discusiones liberales y el comunismo.

En segunda instancia, le encomienda una misión a España: retomar la Reconquista del Mediterráneo con una Cruzada «civilizadora». Dentro de su intención apologética del cristianismo como agente de progreso y bienestar, Ozanam posiciona al islam como el enemigo por derrotar, a pesar de los problemas inter-

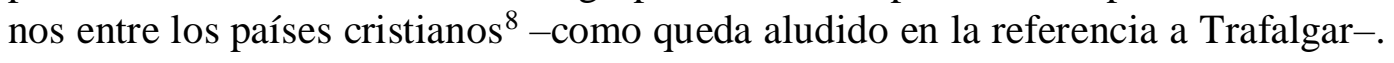

\footnotetext{
${ }^{8}$ Previamente había referido la situación histórica del siglo XV, cuando los españoles se encontraban en un conflicto interno a pesar de la amenaza musulmana en Andalucía: «Le quinzième siècle est encore un siècle tragique. Les chrétiens d'Espagne se déchirent et s'entre-tuent, pendant que sur les tours de Grenade les infidèles veillent en attendant l'heure de se jeter sur la Castille épuisée» (Ozanam, 1869: 91). Esta reflexión sobre la falta de unión de los cristianos se vincula claramente
} 
Es peculiarmente interesante que el autor se permita este consejo, pero lo escriba en francés a un enunciatario que evidentemente se construye como francófilo y, sin embargo, no realice ningún tipo de mención al rol que desempeñaría Francia si España decidiera hacerlo; parecería que Francia no estaría destinada a defender la cristiandad, aunque geográficamente comparte gran parte de los rasgos enumerados que se lo facilitarían.

En consecuencia, estos objetivos apologéticos responden a las exigencias y necesidades de la Francia del siglo XIX, perturbada por las revoluciones y las persecuciones, escindida socialmente por la lucha de clases y con una Iglesia clericalmente debilitada, en la cual cobran protagonismo los fieles laicos, mediante sus obras de caridad como así también en la vida política e intelectual, a pesar de su división interna. Esto se encuentra en consonancia con lo indicado por Iñarrea Las Heras (2015: 322) acerca de los viajeros franceses que peregrinaban a Santiago de Compostela en el siglo XIX: «Ils voient l'Espagne comme une sorte de réserve spirituelle de l'Occident: la seule vraie religion et la croyance des Espagnols y restent pour le moment intactes». Ozanam, precursor de lo que sería la Doctrina Social de la Iglesia, se construye en su relato como un referente del cristianismo y busca en su viaje por España sus frutos, que sintetiza en tres ejes del itinerario: el heroico, el real y el devocional.

En síntesis, luego de haber examinado todos estos rasgos constitutivos y haberlos ejemplificado con algunos pasajes, podemos afirmar que Un pèlerinage au pays du Cid se configura como un relato de viajes, dado que se trata de un discurso narrativo-descriptivo en tanto refiere acontecimientos de un itinerario, pero carece de tensión climática: cumplen una función caracterizadora, representativa. De esta manera, el objeto final del texto es presentar un fragmento de mundo, una visión sobre España, esto es, una construcción a partir de las vivencias reales, de las lecturas y del pensamiento de Fréderic Ozanam. Las decisiones tomadas sobre el material del viaje y las operaciones discursivas efectuadas, ya sea la selección, la jerarquización o la transformación, responden a las expectativas de sus lectores pretendidos y a las demandas de su contexto histórico: sobre todo, la necesidad de defender y recuperar el cristianismo en Europa. España encarna entonces un refugio espiritual esperanzador.

\section{La construcción de la España visitada}

La España representada por Frédéric Ozanam en Un pèlerinage au pays du Cid se nutre no solo de la experiencia del viaje de 1852, sino también de sus lecturas históricas, literarias y legendarias, y de la imagen del país y sus habitantes en el imaginario cultural francés de la primera mitad del siglo XIX. Al analizar la representación gestada por Ozanam de Alemania, a raíz de sus viajes y estudios literarios, Maurer (2014: 47) señala esta misma mediación:

con las circunstancias de su Francia del siglo XIX. Lo mismo sucederá con su valoración de las figuras de Fernán González y el Cid, tal como analizaremos en el apartado 3.2. 
On peut cependant souligner qu'à l'instar de l'image que renvoie le récit de ses voyages l'Allemagne de Frédéric Ozanam est davantage une Allemagne rêvée, idéalisée, qu'une Allemagne réelle: sinon une Allemagne des poètes et des penseurs, du moins une Allemagne des récits mythiques, des hagiographies, des écrivains et des historiens du Moyen Âge.

Es un procedimiento típico de los libros de viaje, tal como apunta Alburquerque-García (2006: 81):

Los libros de viaje reflejan en cierta manera los intereses, inquietudes y preocupaciones de cada época, cultura y situación implicadas en el itinerario abarcado por el relato. Además, el tipo de información proporcionada por el viajero/escritor es bidireccional, es decir, que ilustra tanto sobre la cultura visitada como sobre el bagaje cultural y los prejuicios del que visita. Este género literario apunta, por tanto, no sólo a la literatura de origen del autor sino también a la literatura de las culturas en él representadas.

Como objetivo de la travesía de Ozanam, enunciado explícitamente, se encuentra la recuperación de la vieja España católica, de sus tradiciones y acontecimientos, mas en defensa de una tesis: el impacto positivo del cristianismo en la Edad Media en términos de la historia de la civilización. Con tal fin, se emplean distintas redes isotópicas, que operan en el nivel de la coherencia semántica, como así también numerosos intertextos, cuyo análisis revelará que no solo cumplen una función descriptiva fundamental, propia del relato de viajes, sino que también se presentan con una carga valorativa significativa.

\subsection{La red isotópica}

El análisis detallado de los distintos tipos de descripciones brinda un repertorio de temas que reiteradamente se manifiestan en un texto. Los elementos explícitos configuran las isotopías, en tanto «conjunto redundante de categorías semánticas que hacen posible la lectura uniforme del relato» (Greimas, 1973: 222), categorías que sostienen la coherencia interna de los relatos de viajes como discursos descriptivos al construirse por la recurrencia de lexemas pertenecientes a un mismo campo semántico. El relato de viaje de Ozanam posee una variedad de ellas, pero no se encuentran desasociadas, sino que se construyen en una red con oposiciones: la naturaleza como obra de Dios y la obra del hombre; la modernidad opuesta a la tradición; los vivos -identificados con el ruido y el movimientoopuestos a los muertos -la quietud, las ruinas, la historia, especialmente la Edad Media-. Las distinguiremos por razones metodológicas y expositivas, pero se podrá comprobar que en realidad estas isotopías se encuentran entramadas.

\subsubsection{La naturaleza como obra de arte de Dios vs. la obra del hombre}

En el primer apartado, Ozanam se detiene en los paisajes de la frontera francesa, especialmente Gavarnie y Biarritz. Destaca que, por ser lugares poco 
habitados o intervenidos por el hombre, allí se pueden apreciar superlativamente las obras divinas: «Dans ce pays-ci, où l'homme a peu fait, je ne vois plus que les œuvres de Dieu. Vraiment Dieu n'est pas seulement le grand législateur, le grand géomètre, il est aussi le grand artiste» (Ozanam, 1869: 5). A partir de esta definición de Dios como «el gran artista», compone una descripción del espectáculo natural del circo de Gavarnie:

Quel poëte n'a jamais conçu, quel architecte n'a jamais dessiné un sanctuaire comparable à celui que l'Éternel s'est bâti à lui-même au plus profond des Pyrénées, dans un lieu où il n'était adoré que par des pâtres ? On l'appelle le Cirque de Gavarnie. Mais, plutôt qu'un cirque, représentez-vous l'abside d'un temple, taillée à pic dans des rochers hauts de deux mille quatre cents pieds. Quand nous arrivâmes au bas de ces murailles prodigieuses, des nuages rougis par le soleil couchant en voilaient le sommet et flottaient comme une draperie. Puis, quand le vent eut dissipé ces vapeurs, le faîte de l'édifice parut couronné de neiges éternelles sous le pavillon bleu du firmament (Ozanam, 1869: 6).

Se observa con claridad el recurso de la comparación: el circo de Gavarnie es asimilado a un templo -lugar sagrado por excelencia, pero construido por el hombre- en una descripción que resulta inusualmente intensa en contraste con otras de Un pèlerinage au pays du Cid, ya que está poblada de preguntas retóricas, adjetivación plena en rasgos sensoriales y comparaciones.

Esta equiparación de Gavarnie con un templo propone no solo a Dios como artista, sino también un carácter marcadamente positivo respecto al arte, ya que también Él quiso lo bello:

Ne méprisons plus la poésie comme le rêve des imaginations malades ou comme le passe-temps des sociétés blasées. Dieu est l'auteur de toute poésie, il l'a répandue à pleines mains dans la création, et, s'il a voulu que le monde fût bon, il l'a aussi voulu beau (Ozanam, 1869: 5-6).

En efecto, Ozanam valora el arte, especialmente cristiano, pero siempre como una obra imperfecta frente a la Creación de Dios, el ideal, por eso es incesante y numeroso, transgeneracional:

Il est temps de franchir le seuil: alors cet édifice, qui par sa légèreté semblait un joyau, devient immense et semble un monde. Mais c'est un monde que Dieu remplit; et en effet un symbolisme divin a remué ces pierres et leur a donné la pensée, ou, ce qui est plus encore, la force de vous faire penser, vous et les générations qui avant vous s'agenouillèrent ici (Ozanam, 1869: 124-125).

À Burgos, comme dans quelques-unes des grandes basiliques d'Italie, comme à Venise à Adoue, à Florence, on n'a jamais fini de voir, parce que l'art chrétien n'a jamais fini de créer. Dieu s'est reposé le septième jour ; ce qu'il avait fait 
était bien et réalisait pleinement son idée créatrice. Mais l'art chrétien ne se repose jamais, parce qu'à ses yeux ce qu'il a fait n'est pas bien et demeure éternellement au-dessous de l'idéal (Ozanam, 1869: 130).

Enmarcada dentro de esta reflexión estética, también se presenta la pregunta formulada por la mujer en la catedral de Burgos acerca del destino final de las obras arquitectónicas devotas (Ozanam, 1869: 142-143), especialmente cuando provocan un sentimiento pleno de piedad que trasciende la materialidad del arte para conducir al verdadero objeto de adoración: «si cette prédication de la pierre et du bois qui vous a saisi dès l'entrée vous a poursuivi jusqu'ici toujours plus pressante, vous n'admirez plus, vous priez, humilié, anéanti comme le pauvre Espagnol qui déroule sou rosaire à vos côtés» (Ozanam, 1869: 129). Esto se vincula con el análisis que realiza Franconnet (2014 : 93) sobre la concepción del arte de Ozanam: «Ozanam oppose l'art païen -qui propose un beau idéal naturel- à l'art chrétien, qui aspire à s'élever au-dessus de ce beau idéal naturel».

A pesar de esta apreciación acerca del arte cristiano, al describir el espectáculo de los Pirineos y compararlo con Suiza, Ozanam remarca acerca de la pureza «moral» de la naturaleza impoluta, que no ha sido corrompida por la humanidad:

Je trouve en effet comme un sentiment de pureté morale sur ces hauteurs que le pied de l'homme souille rarement, au bord de ces eaux qui ne désaltèrent que l'isard et l'aigle, au milieu de ces plantes qui ne fleurissent que pour parfumer la solitude (Ozanam, 1869: 7-8).

Un comentario en la misma línea realizará respecto al paisaje de Fuenterrabía, manchado por la historia sangrienta: «Ces grands aspects, la douceur de l'air, la verdure encore toute vive et fraîche clans une saison si avancée, faisaient de ce pays un paradis terrestre, mais un paradis ensanglanté par les passions des hommes [..]» (Ozanam, 1969: 16).

Esa misma «barbarie» encuentra su ejemplo en una tradición española: la corrida de toros. Se siente obligado a asistir a una, dado que se señala como un hito obligado de un viaje a España (Ozanam, 1869: 111), pero lo describe y evalúa negativamente, con un gran énfasis en la emoción provocada:

alors, je l'avoue, je passais tout entier du côté du taureau; je n'avais pas le courage de considérer si le coup était porté selon les règles, je détestais cette boucherie, et je m'enfuyais de l'amphithéâtre, pendant que six mules entraînaient dans la poussière le corps sanglant, au bruit des fanfares et aux applaudissements d'une foule enivrée (Ozanam, 1869: 113; el subrayado es nuestro).

Recuérdese el valor simbólico de la mancha, uno de los símbolos primarios del mal para Paul Ricœur (1976).

\subsubsection{La modernidad vs. la tradición}


La oposición quizás más evidente construida por Ozanam durante el relato de Un pèlerinage au pays du Cid es entre la modernidad y la tradición. No disimula su posicionamiento negativo hacia la modernidad: aprovecha cada restauración o agregado que observa para criticar las «intromisiones» modernas, a las que califica de «vandalismo»: «En même temps le vandalisme des restaurations modernes défigura l'église»(Ozanam, 1869: 49), «Entrons dans la basilique ; oublions les décorations modernes qui déshonorent le sanctuaire» (Ozanam, 1869: 78). Sin embargo, no solo realiza tales comentarios respecto a la arquitectura religiosa: también acerca de aspectos urbanos. Al describir su primera impresión de Burgos en el tercer apartado, propone una imagen desilusionada:

Le premier abord de Burgos n'a rien d'héroïque. On y entre par le faubourg qui suit la rive gauche de l'Arlanzon, en tout semblable à nos faubourgs, bordé d'auberges et d'entrepôts, et qui n'a d'espagnol que les clochers des églises et les galeries suspendues au dernier étage de quelques maisons. [...] Là se déploie la cité de Burgos, avec tous les dehors d'un chef-lieu de province de second ordre (Ozanam, 1869: 2829).

La ciudad contrasta con las expectativas creadas no solo por la literatura, sino también por el título del apartado. En comparación con Francia, no parece tener nada distintivo, nada propio ni importante. Pero luego advierte al lector lo que oculta esta prosperidad aparente: «Mais si vous conservez une âme chimérique, si vous êtes épris de ruines et d'infortunes, consolez-vous: cette prospérité apparente ne fait que vous cacher des rues abandonnées, des espaces déserts où quelque décombre garde un grand nom» (Ozanam, 1869: 28). Describe así el típico espíritu romántico del viajero de la época, más interesado en las ruinas y en la historia que en el progreso industrial o urbano. Obsérvese que tales espacios son caracterizados como deshabitados, abandonados, lo cual los vincula con la isotopía de los muertos que se analizará en 3.1.3. Conviven en una misma ciudad la modernidad y la tradición, como prosigue a describir utilizando la imagen de la hiedra y las ruinas:

Au nord de la ville moderne, et en redescendant vers l'ouest, se déroule l'antique ceinture de murailles, à demi détruites, mais larges encore et menaçantes, couronnées de créneaux et percées de portes dont l'arcade en fer à cheval rappelle le temps des Maures. La tradition s'attache comme le lierre à ces vieux débris (Ozanam, 1869: 29).

Las murallas con sus herraduras evocan el tiempo de los moros, la época de la Reconquista, la victoria del cristianismo. La historia se adhiere y filtra entre los muros, a la manera de la hiedra. Este mismo énfasis en el valor de la resistencia contra la modernidad se observa en la descripción del pueblo vasco francés, particularmente su negación a aceptar los pantalones y la blusa, conservando su vestimenta tradicional (Ozanam, 1869: 9). También admira su memoria, especialmente la conservación de la lengua ancestral (Ozanam, 1869: 11-12). 
Otra instancia de contraste entre la modernidad y lo tradicional se advierte en la valoración que realiza Ozanam (1869: 58-59) de la hospitalidad española: no habrá hoteles espléndidos como en Londres o París, pero sí grandes cocinas «heroicas», repletas de utensilios caseros. Asimismo, defiende la devoción española por los santos y la Virgen María como rasgo propio: manifiesta que no debe tratársela desdeñosamente, sino como una piedad que tiene claro su centro en Cristo y que, además, resulta efectiva, dado que sus iglesias están pobladas (Ozanam, 1869: 133-134). En este mismo sentido, realza a Fernán González y al Cid como figuras de la defensa de la conservación de la tradición de la autoridad, tal como se fundamentará en la sección de intertextos, 3.2.2.

Esta oposición a la modernidad es otro rasgo en común con otros viajeros franceses de la época y es provocada por la nostalgia de una época percibida como mejor en términos de la fe cristiana, tal como manifiesta Iñarrea Las Heras (2015: 334):

Les voyageurs-écrivains étudiés ici apparaissent comme les défenseurs d'une vision du monde dépassée par l'évolution politique, sociale et économique de la France et de l'Espagne. Ils se caractérisent, en général, par une nostalgie d'un passé ou, à leur avis, la situation de la foi catholique était meilleure. Ils sont les témoins indignés et affligés d'un présent qu'ils déplorent, puisqu'ils considèrent qu'il est dépourvu des valeurs chrétiennes.

\subsubsection{Los vivos, el ruido, el movimiento vs. Los muertos, la quietud, las rui- nas, la historia}

En el apartado anterior se ha observado la preferencia por las ruinas, signos de la historia, en vez de los aspectos modernos de las ciudades. Defiende el itinerario elegido basándose en ese criterio, como la manera adecuada de ingresar y conocer España: «On y entre comme il convient d'entrer en Espagne, par des ruines, par une porte menaçante et des remparts croulants» (Ozanam, 1969: 16). Es conveniente recordar su comentario acerca de la necesidad de dotar de vida a tales restos mediante las referencias históricas, literarias y legendarias, que nos transportan en el tiempo (Ozanam, 1869: 85). Resalta particularmente el poder de la poesía para lograrlo:

Dans le poëme du Cid comme dans les épopées homériques, nous touchons au fond primitif de toute poésie. De même que, sous l'œuvre d'Homère, on découvre les chants guerriers dont il a recueilli, transformé et fait vivre les débris ; de même l'épopée castillane, écrite au treizième siècle, a recueilli l'écho des chansons non écrites où l'on célébrait déjà l'invincible Rodrigue (Ozanam, 1969: 57).

Se destaca como característica de los muertos y de las ruinas la soledad o el carácter desértico, especialmente en aquellos lugares donde las causas son históricas, en particular la guerra contra el Infiel: 
Ce sont les gorges de Pancorbo, teintes du sang des infidèles au neuvième siècle: les restes d'un château dominent la bourgade désolée. On dirait que la guerre vient de passer sur ces villages en ruine, sur ces maisons sans vitres, quelquefois sans portes, et cependant bâties en pierres de taille, comme pour soutenir des sièges (Ozanam, 1869: 23; la cursiva es nuestra).

Se caracteriza Pancorbo por la carencia y la desolación, además de retomarse el rasgo de la mancha de sangre generada por los humanos. Estas privaciones le permiten profesar cierta objetividad, o al menos rechazar la posibilidad de una representación romántica o idealizada de Burgos de su parte:

Pour moi, je n'aurais pas réveillé les vieux morts de Burgos, si je n'avais bravé les tempêtes déchaînées pour défendre leur solitude. Il est vrai, j'ai vu la ville royale sous un voile, mais sons un voile de pluie peu favorable aux illusions (Ozanam, 1869: 63).

Sin embargo, frente al carácter desértico de estas ruinas, se genera un contrapunto: se encuentran pobladas de historia. En consecuencia, se opera una identificación entre las ruinas, la historia y los fallecidos silenciosos y solitarios, en contraste con los vivos, descritos con el ruido y el movimiento: «Je ne puis pas oublier le cloître tout habité de morts illustres et silencieux, et de vivants obscurs, mais très-bruyants» (Ozanam, 1869: 130). Valora el respeto por los muertos como rasgo esencial de un pueblo, en tanto representa la deferencia por la familia y la tradición, implícitamente también por su historia:

Mais plus encore que son jeu de paume, chaque village entretient avec jalousie son cimetière: ce lieu de deuil est tout planté de rosiers; on y voit peu de sépultures délaissées, et nul n'entre à l'église sans avoir prié sur la tombe des siens. Le culte des morts est le signe des races qui vivent longtemps, qui ne laissent perdre ni l'esprit de famille ni l'héritage des traditions (Ozanam, 1969: 10).

Asimismo, recuérdese que en el prólogo la primera motivación esgrimida para emprender un viaje a España era la peregrinación a Santiago de Compostela, que fundamenta con una remisión a la tradición de los antepasados (Ozanam, 1869: 2).

En contraste, expresa horror ante las profanaciones y el tratamiento de los restos de Rodrigo Díaz de Vivar, héroe de Castilla:

Ce n'était pas sans quelque doute sur leur authenticité, mais ce n'était pas non plus sans mélancolie que je contemplais ces restes, montrés pour deux réaux par un valet qui leva le drap funéraire et ouvrit le cercueil. J'ai horreur de ce qui viole le secret de la mort, et je ne puis souffrir le spectacle de ces ossements desséchés, à moins que la sainteté n' ait jeté sur eux un vêtement impérissable (Ozanam, 1869: 50). 
La muerte evocada mediante las ruinas y su contraste con la vida circundante también es recuperada a nivel religioso, en referencia al misterio de la Resurrección y la esperanza que genera: «l'église, seule intacte au milieu de cette ville délabrée, comme pour rappeler que le Dieu des ruines est aussi celui des résurrections. Fontarabie ne se tient pas pour morte [...]» (Ozanam, 1969: 17-18), «Mais entrez dans ce séjour de la mort: vous y trouverez toute la splendeur des esperances chrétiennes» (Ozanam, 1869: 96, acerca de la iglesia de Miraflores).

Sin embargo, la asociación axial en este plano se encuentra en la valoración que realiza el escritor francés de la Edad Media, particularmente del rol civilizador y cultural desempeñado por el cristianismo: «Enfin le riche hameau de Gamonal annonce les approches de Burgos; et les tours de la cathédrale, qui se découvrent, publient qu'un jour, sur cette terre aride et indigente, l'inspiration chrétienne est descendue»(Ozanam, 1969: 26 ). Pero aún más explícita es la siguiente cita:

Si les rois ont délaissé Burgos, la vieille ville a gardé une reine qui la fait vivre, qui n'a pas cessé d'y habiter une magnifique demeure. Cette reine est la Vierge Marie. En effet, la capitale de l'ancienne Castille, abandonnée de sa noblesse, sans commerce, sans industrie, aurait péri depuis longtemps si elle n'avait conservé sa vie ecclésiastique, son rang de métropole et son incomparable cathédrale (Ozanam, 1869: 115).

No solo señala los efectos arquitectónicos del cristianismo, también subraya su influencia en la literatura del Siglo de Oro, particularmente en Calderón:

Cette poésie [del siglo XV], qui s'était contentée de mesures incorrectes et d'assonances faciles, devait s'assouplir et se montrer capable de la dernière précision et de la plus exquise mélodie. Il fallait qu'elle passât par un long apprentissage avant d'arriver au moment où Caldéron, retrouvant l'inspiration des plus beaux temps chrétiens, lui donnerait tout le prestige d'un langage étincelant et musical, intraduisible pour nous, éternellement enchanteur pour l'oreille des Espagnols (Ozanam, 1869: 93-94; el subrayado es nuestro).

También destaca la capacidad de la religión de moderar la crueldad de los reyes y de ser fundamento de obras trascendentales: «Partout des autels, des mausolées, de pieuses images attestant la foi de ces familles orgueilleuses, violentes, mais après tout capables de religion et de repentir [...]» (Ozanam, 1869: 67). En un mismo sentido, subraya la facultad del cristianismo de templar la rudeza de los tiempos de Reconquista: «Voilà les temps héroïques de la Castille dans leur force et leur rudesse, tempérées par la douceur du christianisme» (Ozanam, 1869: 52).

Otro rasgo que destaca de la Edad Media es su tratamiento honroso de la mujer, especialmente en el caso de España la protección eclesiástica y el poder otorgado a las damas del monasterio de Santa María la Real de las Huelgas: 
De leur côté, les papes ne purent refuser ces honneurs étranges aux filles d'une race royale qui soutenait contre les infidèles une croisade de huit cents ans. Nulle part plus qu'en Espagne les femmes n'eurent besoin d'être protégées par le respect, parce que nulle part ne leur manqua davantage la protection de l'épée, le rempart de la famille; nulle part elles ne furent condamnées à une plus longue solitude, à des veuvages plus certains, quand une guerre éternelle retenait leurs maris et leurs frères. [...] Le moyen âge honora partout les femmes chrétiennes: en France et en Italie, il mit à leur service des guerriers et des poètes; en Castille, il rangea sous leurs lois des religieux et des prêtres (Ozanam, 1869: 76).

Asimismo, recalca la caridad cristiana como un rasgo fundamental del pueblo español, al referir la leyenda del santo Amaro y del Hospital del Rey (Ozanam, 1869: 81-83).

\subsection{Los intertextos literarios}

Para Alburquerque-García, la intertextualidad es uno de los rasgos definitorios de los relatos de viaje, dado que se nutren tanto de la experiencia factual del viajero como de la lectura de textos anteriores -a veces no tan fácilmente clasificables-, que pueden operar como guías, indicios o huellas que condicionan la percepción y la interpretación. En consecuencia, la presencia de intertextualidad «nos alerta sobre las diferentes y variadas familias de relatos que dialogan entre sí, cuyas resonancias nos hablan de tradición e influencias culturales» (AlburquerqueGarcía, 2011: 18).

Un pèlerinage au pays du Cid es un ejemplo representativo de este diálogo cultural, ya que es un relato de viajes construido con un entramado intertextual abundante. Son recurrentes las referencias a las leyendas, la literatura y la historia de España, especialmente medieval y siglodorista: sintetiza y se refiere al Cantar del Cid, al Poema de Fernán González, distintas crónicas, romances de distinta temática, diferentes leyendas de vidas de santos; entre los autores, se citan fragmentos o se alude a Jorge Manrique (Ozanam, 1869: 107-108), Juan de Mena (el Cancionero de Baena; Ozanam, 1869: 91-92, 105-107), el canciller Ayala (Ozanam, 1869: 62-63), Gil Vicente (Ozanam, 1869: 150-151), Garcilaso de la Vega y Jorge de Montemayor (Ozanam, 1869: 19-20), hasta Calderón de la Barca (Ozanam, 1869: 93-94).

Solo existe una referencia al Quijote en todo el relato y es particularmente curiosa. Luego de describir las cocinas españolas, recurriendo a diversos recursos sensoriales para vivificar la escena, el autor siente la necesidad de justificar literariamente su descenso a este espacio mundano:

Nous vivrons, et vous ne m'en voudrez pas d'être redescendu de mes hauteurs poétiques à ces utiles réalités.

Nous n'avons pas même, à vrai dire, quitté la littérature espagnole; car, si le poëme du Cid naît sur les champs de 
bataille, c'est d'une cuisine d'auberge que don Quichotte sort chevalier pour combattre les géants et redresser les torts (Ozanam, 1869: 60).

En consonancia con la cita quijotesca, existe una previa referencia homérica inusual y humorística. Al ponderar las cocinas españolas como una hospitalidad sublime, se compara la cantidad de ollas con un episodio la Odisea: «Je contemplais surtout des files de marmites qui me rappelaient (pardonnez-moi encore cette réminiscence d'Homère) la longue file des servantes de Pénélope que Télémaque pend à la même corde en punition de leur perfidie» (Ozanam, 1869: 59).

Aparte de la literatura española y Homero, también se emplean ocasionalmente otros intertextos, tales como pasajes bíblicos de los Salmos y el Apocalipsis, alusiones míticas griegas, literatura latina -Horacio-, italiana -especialmente Dante, pero también reflexiona sobre el influjo de la poesía provenzal e italiana en el renacimiento español-, inglesa -exclusivamente Milton (Ozanam, 1869: 6-7)- y francesa -Chanson de Roland (Ozanam, 1869: 145)-.

Utiliza los intertextos con una función descriptiva y contrastiva. De esta manera, por ejemplo, su experiencia del clima poco grato de Castilla es comparada con las de Horacio y Dante en Italia:

Devais-je m'étonner des neiges de Rome et des eaux du Tibre grossissant sous les orages, quand Horace déjà s'en prenait à Jupiter de l'opiniâtreté des frimas, et croyait revoir sous Auguste le déluge de Deucalion ? Et lorsque Dante, au troisième cercle de son Enfer, décrit la pluie «éternelle, maudite, froide et triste», certainement il en trouve l'image sur les bords de l'Arno, à Pise, où moi, indigne commentateur, pour l'éclaircissement de ce seul vers, j'ai vu pleuvoir cinquante jours (Ozanam, 1869: 62; cita en notas los versos en latín).

En lo que concierne a la influencia de la literatura provenzal e italiana en España, sostiene taxativamente: «Mais surtout le quinzième siècle, en s'appliquant à reproduire les rythmes des Italiens et des Provençaux, en poussant jusqu'à l'excès la ciselure du vers et de la stance, faisait subir un travail nécessaire à la rude langue du Cid» (Ozanam, 1869: 93; la cursiva es nuestra) .

Sirvan estos ejemplos para ilustrar el procedimiento de los intertextos, ya que en lo sucesivo nos detendremos solamente a analizar aquellos que colaboran o agregan algún aspecto significativo sobre la representación de la España visitada o el objetivo del relato.

Los intertextos bíblicos se encuentran en el primer apartado especialmente vinculados con la isotopía de la naturaleza como obra de Dios, para retratar el efecto de admiración que genera, por ejemplo, respecto al Pirineo: «David avait vu de près les sommets du Liban, quand il s'écriait : "Le Seigneur est admirable sur les lieux hauts Mirabilis in altis Dominus"'»(Ozanam, 1869: 8), o la inmensidad del mar: «David avait aussi admiré ce spectacle, et peut-être du haut du Carmel son regard embrassait-il les espaces mouvants de la Méditerranée lorsqu'il 
s'écriait: "Les soulèvements de la mer sont admirables Mirabiles elationes maris"” (Ozanam, 1869: 14). En cambio, en sintonía con la referencia al caos del Paraíso Perdido de Milton, se describe la furia del mar comparándola con los caballos del Apocalipsis: "Ces mêmes vagues, si caressantes maintenant, ont des heures de colère où elles semblent dé-chaînées comme les chevaux de l'Apocalypse; alors leurs blancs escadrons se pressent pour donner l'assaut aux falaises démantelées qui défendent la terre» (Ozanam, 1869: 13).

Las referencias homéricas son más numerosas y se encuentran distribuidas en todo el relato en función de diversas isotopías. Respecto a la naturaleza como obra divina, se utiliza para describir la combinación de infinitud y gracia del mar:

Mais que dire de la mer, ou plutôt que n'en faut-il pas dire? La grandeur infinie de la mer ravit dès le premier aspect; mais il faut la contempler longtemps pour apprendre qu'elle a aussi cette autre partie de la beauté qu' on appelle la grâce. Homère le savait bien, et c'est pourquoi, s'il donnait à l'Océan des dieux terribles et des monstres, il le peuplait en même temps de nymphes et de sirènes enchanteresses (Ozanam, 1869: 12).

También se aplica como término de comparación para representar la infinitud de las obras arquitectónicas religiosas: «Je ne vous entraînerai pas dans la visite des chapelles: autant, vaudrait dé nombrer avec Homère les vaisseaux des Grecs!» (Ozanam, 1869: 134).

Sin embargo, con mayor frecuencia se comparan las obras homéricas con el Cantar del Mio Cid en distintos aspectos. En primer lugar, en tanto obras épicas, ambas literaturas construyen una imagen de heroísmo. La identificación entre el Cid y Aquiles es tal que es usado directamente como epíteto: «L'Achille de l'Espagne ne restera pas en repos sous sa tente; au bout de sa lance désormais libre et souveraine, il porte la guerre aux mécréants»(Ozanam, 1869: 46). Esta imagen de heroismo para Ozanam se encuentra asociada con la capacidad para el engaño: «Ainsi chante la ballade espagnole: les peuples mêlent volontiers à leurs origines la ruse et l'héroïsme. Carthage se souvenait de la peau de bœuf qui avait mesuré son territoire, et toute la Grèce met tait à côté d'Achille l'artificieux Ulysse» (Ozanam, 1869 : 34-35). Pero enseguida se demuestra un contraste entre los héroes clásicos y el héroe español: su honor cristiano, incluso frente a los judíos:

Mais, quand le Cid eut pris Valence, il renvoya les trois cents marcs d'argent et les trois cents d'or pour dégager ses deux coffres de sable, «priant Rachel et Bidas de lui pardonner, car il l'avait fait avec chagrin ». Ce dernier trait me touche. Je croyais le Castillan ravi d'avoir joué un si bon tour à deux infidèles. Mais son honneur chrétien en souffre, et il a besoin de pardon (Ozanam, 1869: 45-46).

Asimismo, se diferencian los tipos de ira: 
L'antagonisme des chefs de guerre et du souverain politique se fait jour en Espagne comme en Grèce; la dispute éclate entre le Cid et Alfonse VI, comme entre Achille et Agamemnon. Mais la colère du Cid est chrétienne, elle éclate clans une église et pour de graves soupçons [...] (Ozanam, 1869: 39-40).

Luego distingue las causas de las guerras, en este caso, la defensa de la fe y de la nación cristiana ante la amenaza del infiel (Ozanam, 1869: 62-63). Tanto el enfrentamiento del Cid como de Fernán González con la autoridad gobernante es justificada por la defensa de tradición y de la libertad del pueblo -y valorada positivamente-:

Ensuite vient la passion de l'indépendance, non-seulement de l'indépendance personnelle, mais des libertés castillanes. [...] Il ne faut point voir en eux, comme on l'a trop fait, des factieux, des ennemis de toute loi. Ils se portent au contraire pour les défenseurs des lois anciennes, des fueros, que le peuple défendra encore contre Alfonse X, contre ses légistes et son code des Siete partidas (Ozanam, 1869: 54) 9

El tercer rasgo de la épica castellana que le impresiona a Ozanam son los afectos domésticos: se refiere al hermano que venga a los siete infantes de Lara, como así también a la ayuda de la esposa que libera a Fernán González dos veces, como al Cid, en todos sus roles: de hijo, lavando el honor de su padre; de padre, restituyendo la honra de sus hijas; de esposo, con su ternura hacia su esposa (Ozanam, 1869: 54-58). Al retratar todas estas escenas, culmina con una comparación entre la despedida de Rodrigo y Jimena y la de Héctor y Andrómaca: «Vous reconnaissez l'accent des adieux d'Andromaque et d'Hector, avec la majesté chrétienne de plus; de moins une grâce et un éclat dont la muse grecque a le secret» (Ozanam, 1869: 57).

A pesar de la «rudeza» de la lengua del Poema del Mio Cid, se destaca sobre las obras homéricas en función de su «majestuosidad cristiana», signo civilizador. En ambos casos se reconoce «el fondo primitivo» de toda poesía y su capacidad de «revivir» a estos grandes héroes, en sintonía con las isotopías previamente abordadas.

\section{Conclusiones}

9 En este sentido, cabe detenerse en la valoración que realiza ante la estatua de Fernán González: «Un monument plus considérable, mais d'un moindre caractère, marque le lieu où fut la maison de Fernan Gonzalez. Qui croirait que Philippe II, l'ombrageux monarque, érigea cet arc de triomphe en l'honneur du grand comte de Castille, qu'on voit souvent armé contre les infidèles, mais toujours l'épée au poing contre les rois?» (Ozanam, 1869: 31). Considero que la incredulidad de Ozanam ante el reconocimiento del rey Felipe II tiene un fundamento en su contexto coetáneo, más que histórico: le resulta insólita la capacidad de un gobernante de apreciar a un oponente, priorizando primero la unidad nacional y la defensa de la religión y la tradición, sobre otros aspectos políticos. Esa incapacidad es probablemente la causa del fracaso de la Segunda República para Ozanam. 
En el presente trabajo nos hemos propuesto analizar la configuración del discurso en Un pèlerinage au pays du Cid desde una perspectiva formal en lo que concierne a sus componentes constitutivos -el objeto del viaje, el enunciador, el enunciatario y la estructura- con el fin de determinar su clasificación genérica. Se ha demostrado que se trata de un relato de viajes, en tanto que la función descriptiva es predominante en este discurso narrativo-descriptivo, en correspondencia con su finalidad de presentar un espectáculo imaginario (Carrizo Rueda, 1997: 28), en este caso, una representación de la España tradicional, católica y medieval, tal como la concibe Ozanam a partir de sus lecturas literarias e históricas, en respuesta a su propio contexto histórico de producción: la situación de Francia, y particularmente de los católicos, a mediados del siglo XIX.

Ozanam pretende defender el rol desempeñado por el cristianismo en la historia y ese es el eje que se despliega mediante las redes isotópicas construidas: la naturaleza como obra de arte de Dios, contrapuesta a la imperfecta obra del hombre; la modernidad contrapuesta a la tradición; los vivos, identificados con el ruido y el movimiento, contrapuestos a su vez a los muertos, caracterizados por la quietud, la soledad, las ruinas, la historia. Aquello que puede integrar a estos binarismos es el arte, tanto plástico como poético, como un puente entre la historia y el presente, entre Dios y los hombres, siempre y cuando que tenga su fundamento en la fe cristiana. Los numerosos y variados intertextos también se disponen de una manera similar, aunque hemos optado por analizar aquellos rasgos llamativos que revelan o subrayan aspectos de esta España representada en tanto indicios de la finalidad apologética subyacente del autor francés.

Más allá de las intenciones con las cuales opera sobre el material, cabe destacar la labor de Ozanam en lo que respecta a su investigación acerca de la literatura y la historia medieval española, considerando el estado tan preliminar en el cual se encontraban los estudios del área, mucho más en las lenguas accesibles para él. Asimismo, la construcción del relato es efectiva en lo que concierne a la presentación de los datos documentales, ya que logra evitar el tedio y vivificar la escena, con diversos procedimientos que hemos analizado en este trabajo, sin que las referencias históricas o literarias se perciban heterogéneas o tangenciales.

Si bien Un pèlerinage au pays du Cid no presenta una España idealizada, sí queda representada según la visión de Frédéric Ozanam, un viajero que responde al prototipo de la época en cuanto se nutre de la literatura y la historia, y quien selecciona, ordena y construye este itinerario textual entre ruinas y discursos.

\section{REFERENCIAS BIBLIOGRÁFICAS}

ALBURQUERQUE-GARCÍA, Luis (2006): «Los "libros de viaje" como género literario», in Manuel Lucera Giraldo \& Juan Pimentel (ed.), Diez estudios sobre literatura de viajes. Madrid, Consejo superior de investigaciones científicas, 67-88.

ALBURQUERQUE-GARCÍA, Luis (2011): «El relato de viajes: hitos y formas en la evolución del género». Revista de Literatura, LXXIII, 145, 15-34. 
BAUDRILlarT, Alfred (1912): Ozanam Frédéric. París, Bloud.

CARrizo Rueda, Sofía (1997): Poética del relato de viajes. Kassel, Reichenberger.

CARRIZO RUEDA, Sofía [ed.] (2008): Escrituras del viaje: construcción y recepción de «fragmentos del mundo». Buenos Aires, Biblos.

Cholvy, Gérard (2003): Frédéric Ozanam, l'engagement d'un intellectuel catholique au XIX $X^{e}$ siècle. París, Fayard.

CojAzZi, Antonio (1933): Federico Ozanam. Buenos Aires, Librería Santa Catalina.

FRANCONNET, Christine (2014): «Frédéric Ozanam et l'art». Revue d'Histoire de l'Eglise de France, 100 (244), 81-94.

GenETTE, Gérard (1989): «Discurso del relato. Ensayo de método», in Figuras III. Barcelona, Lumen, 75-327.

GREIMAS, Algirdas Julien (1973): En torno al sentido. Ensayos semióticos. Madrid, Fragua.

IÑARREA LAS HERAS, Ignacio (2015): «Les récits en français des voyageurs-pèlerins en Espagne à la fin du XIX ${ }^{\mathrm{e}}$ siècle: un témoignage historique et idéologique». Çédille, revista de estudios franceses, 11, 313-340. URL: https://www.ull.es/revistas/index.php/cedille/article/view/1512/1004.

MAURER, Catherine (2014): «Frédéric Ozanam et l'Allemagne : extériorité et attirance». Revue d'histoire de l'Église de France, 100 (244), 37-47.

Nougué, André (1982): «La ciudad de Burgos vista por los viajeros franceses en el siglo XIX». Boletín de la Institución Fernán González, 198, 133-160. URL: http://riubu.ubu.es/bitstream/10259.4/2064/1/0211-8998_n198_p133-160.pdf.

Ozanam, Frédéric (1865): Euvres complètes de A.-F. Ozanam. Volumen XI (Lettres de Frédéric Ozanam 1842-1853). París, Librairie Jacques Lecoffre-Lecoffre Fils et Cie.

Ozanam, Frédéric (1869): Un pèlerinage au pays du Cid. París, Soye.

RICEUR, Paul (1976): Introducción a la simbólica del mal. Buenos Aires, Megapolis.

Romero CARRANZA, Ambrosio (1976): Ozanam y sus contemporáneos. Buenos Aires, Difusión. 